\title{
BMJ Short sleep and obesity in a large Open national cohort of Thai adults
}

\author{
Vasoontara Yiengprugsawan, ${ }^{1}$ Cathy Banwell, ${ }^{1}$ Sam-ang Seubsman, ${ }^{1,2}$ \\ Adrian C Sleigh, ${ }^{1}$ Thai Cohort Study Team*
}

To cite: Yiengprugsawan $\mathrm{V}$, Banwell C, Seubsman S, et al. Short sleep and obesity in a large national cohort of Thai adults. BMJ Open 2012;2:e000561. doi:10. 1136/bmjopen-2011-000561

- Prepublication history for this paper is available online. To view these files please visit the journal online (http:// dx.doi.org/10.1136/ bmjopen-2011-000561).

For author footnote see end of the article.

Received 3 November 2011 Accepted 3 January 2012

This final article is available for use under the terms of the Creative Commons Attribution Non-Commercial 2.0 Licence; see http://bmjopen.bmj.com

\author{
${ }^{1}$ National Centre for \\ Epidemiology and Population \\ Health, The Australian \\ National University, \\ Canberra, Australia \\ ${ }^{2}$ Sukhothai Thammathirat \\ Open University, Nonthaburi, \\ Thailand \\ Correspondence to \\ Dr Vasoonatara \\ Yiengprugsawan; vasoontara. \\ yieng@anu.edu.au (or) \\ vasoontara.yieng@gmail. \\ com
}

\section{ABSTRACT}

Objective: To investigate the relationship between short sleep and obesity among Thai adults.

Design: Both 4-year longitudinal and cross-sectional analyses of a large national cohort.

Setting: Thai adults residing nationwide from 2005 to 2009.

Participants: Cohort members were enrolled as distance learners at Sukhothai Thammathirat Open University ( $\mathrm{N}=87134$ in 2005 and 60569 at 2009 follow-up). At 2005 baseline, 95\% were between 20 and 49 years of age.

Measures: Self-reported sleep duration was categorised as $<6,6,7,8$ and $\geq 9 \mathrm{~h}$. For all analyses (2005 and 2009 cross-sectional and 2005-2009 longitudinal), we used multinomial logistic regression models to assess the effect of sleep duration on abnormal body size (underweight, overweight-at-risk, obese). Results were adjusted for an array of relevant covariates.

Results: At the last cohort follow-up in 2009, crosssectional associations linked short sleep $(<6 \mathrm{~h})$ and obesity: adjusted ORs (AOR) $=1.49,95 \% \mathrm{Cls} 1.32$ to 1.68 for women and $A O R=1.36,95 \% \mathrm{Cl} 1.21$ to 1.52 for men. The earlier cross-sectional baseline results in 2005 were quite similar. Longitudinal analysis (2005-2009) of 4-year incremental weight gain (5 to $<10 \%, 10$ to $<20 \%$ and $20 \%+$ ) strongly supported the short sleep-obesity relationship (significant AORs of $1.10,1.30$ and 1.69 , respectively).

Conclusions: The results are internally consistent (2005 and 2009) and longitudinally confirmatory of a short sleep effect on obesity among Thai adults. Further research is needed to elucidate causal mechanisms underlying the sleep-obesity relationship.

\section{INTRODUCTION}

Short sleep has increased in prevalence over the last century ${ }^{1-3}$ and may now be contributing to the obesity epidemic. A causal association is most accepted for children and adolescents. ${ }^{45}$ Evidence remains inconclusive for adults. ${ }^{6-10}$ But recent research has shown that short sleeping young adults are at increased risk of obesity and of pre-diabetic levels of glycosylated haemoglobin. ${ }^{11}$ And many reports suggest potential biological mechanisms linking short sleep and obesity,

\section{ARTICLE SUMMARY}

Article focus

- The association between sleep duration and obesity for adults is controversial and has rarely been examined in middle-income countries.

- The evidence for a short sleep-obesity effect in adults is mostly based on cross-sectional data.

- This study examines both cross-sectional and longitudinal evidence linking short sleep and obesity among a large national cohort of Thai adults.

\section{Key messages}

- Our cohort study revealed a consistent and substantial association between short sleep and obesity among Thai adults.

- The ORs connecting short sleep to obesity were substantial and significant: 1.36 for men and 1.49 for women in 2009; corresponding ORs were similar in 2005 .

- Longitudinal 2004-2009 cohort data confirmed a significant short sleep-weight gain relationship with a notable dose-response.

Strengths and limitations of this study

n The strength of this study was the large sample, longitudinal data, involvement of young adults and the opportunity to control for many covariates in the analyses.

- One limitation was the subjective nature of selfreporting sleep duration, a problem noted by many others conducting sleep research.

including obstructive sleep apnoea, insulin resistance, stress, high levels of cortisol and ghrelin, low levels of leptin and adiponectin and disordered thermoregulation. ${ }^{12-18}$

The evidence for a short sleep-obesity effect in adults is mostly based on cross-sectional data. ${ }^{7-9}$ However, two large prospective adult cohort studies in the USA report substantive longitudinal weight gain associated with short sleep. $^{19} 20$ Other supportive longitudinal evidence of a short sleep-obesity effect in prospective cohort studies was found among adults in Canada $^{21}$ young adults in Switzerland $^{22}$ and older adults in Spain. ${ }^{23}$ There have been very few longitudinal studies of adults in Asia but one retrospective cohort 
in Japan ${ }^{24}$ and another study of serial population panels in Korea $^{25}$ both show consistent and significant associations between short sleep and obesity.

We examine short sleep and obesity in our large national cohort study of 87134 Thai adults. Our report is based on a longitudinal analysis for the 4-year period from 2005 to 2009 and on cross-sectional analyses at baseline (2005) and follow-up (2009). We investigated the association between sleep duration and weight, adjusting for a wide array of potential confounders.

\section{METHODS AND ANALYSIS}

This study is part of an overarching research project entitled The Thai Health-Risk Transition: a National Cohort Study, which is examining the ongoing transition from traditional to modern patterns of risk and disease. In 2005, the study recruited 87134 distance learning adult students enrolled at the Sukhothai Thammathirat Open University and residing nationwide. ${ }^{26}$ The 20-page 2005 baseline questionnaire covered socio-demographic characteristics, self-reported height and weight (validated), ${ }^{27}$ personal environment, health behaviours, injury and health outcomes.

The Sukhothai Thammathirat Open University cohort is representative of the geodemographic, ethnic composition and income and household assets of the adult Thai population. Based on the results of the 2000 Population and Housing Survey, the median age was 29.2 years for the Thai population and 29.0 years among cohort members, and $51 \%$ of the Thai population were women compared with $54 \%$ of cohort members. ${ }^{26} 2829$ The follow-up study in 2009 reached 60569 cohort members ( $70 \%$ response rate) and the age-sex and geographical distribution of respondents remained almost identical to the baseline. ${ }^{30}$

For body mass index (BMI), we used Asian cut-offs in accordance with studies in other Asian populations based on the International Obesity Task Force. ${ }^{31}$ At baseline in 2005, 95\% of cohort members were aged between 20 and 49 years. Men were twice as likely as women to be overweight (21\% vs $9 \%$ ) and obese (23\% vs $10 \%) .{ }^{32}$ Obesity associated with higher incomes for men and lower incomes for women. ${ }^{33}$ The distribution of BMI by age and sex did not change much by follow-up in 2009.

Sleep duration was measured directly by asking: "How many hours per day do you sleep (including during the day)," categorised as $<6,6,7,8$ and $\geq 9 \mathrm{~h}$. For both 2005 and 2009, we used multinomial logistic regression models to assess the effect of sleep duration on the outcome of abnormal body size (underweight, overweight-at-risk and obese). Thus for short sleepers and normal sleepers, the relative odds for each 'abnormal' weight category versus normal were computed and adjusted for covariates (see below). We also used multinomial adjusted logistic regression to model the longitudinal 4-year incidence of weight gain in three increment categories (see the Results section).
Covariates adjusted in all models included age in years, marital status (married, single and separated/widowed), personal income categories (baht/month), rural-urban geographical residence, self-reported health risk behaviour including smoking (never, current and previous) or drinking (days/week), fruit and vegetable intakes (serves/ day), vigorous or moderate physical activity (sessions/ week), screen time (hours/day), doctor-diagnosed depression and doctor-diagnosed chronic disorders including type I and type II diabetes, high cholesterol, high blood pressure, heart disease, stroke, cancers (liver, lung, stomach, colon, breast and others), goitre, epilepsy, liver disease, lung disease, arthritis and asthma. These covariates were chosen based on our experience with risk factors of obesity in our cohort ${ }^{32-34}$ as well as international literature..$^{35} 36$

We analysed men and women separately as our data show the occurrence of abnormal body size, and the socioeconomic associations vary by sex. ${ }^{32}{ }^{33}$ For data scanning and editing, we used Thai Scandevet, SQL and SPSS software. For analysis, we used SPSS V.16 and Stata V.10. Individuals with missing data $(<10 \%)$ were excluded from multivariable analyses.

\section{RESULTS}

We present the most recent cross-sectional results (2009) and the longitudinal results for 2005-2009 data. The 2005 cross-sectional data were analysed, but results are not shown because they were very similar to 2009. At the follow-up in 2009, cohort weight results were as follows: $9.5 \%$ underweight (BMI $<18.5), 48.5 \%$ normal (18.5 to $<23$ ), $18.4 \%$ overweight-at-risk (23 to $<25)$ and $21.7 \%$ obese $(\geq 25)$. Underweight was most common among women aged between 20 and 29 years $(23.5 \%)$, while overweight-at-risk and obesity were most common among men aged $\geq 45$ years $(28.2 \%$ and $40.3 \%)$.

Among the cohort members responding in 2009, there is a parallel trend between increasing BMI and older age, being married and higher income (table 1). Overweight and obesity increased in frequency with less than four daily serves of fruits and vegetables (especially among men), less than three physical activity sessions per week (especially among women) and $>5 \mathrm{~h}$ of screen time per day (both for men and women). Increased BMI also was more prevalent among those with doctor-diagnosed chronic conditions.

In 2009, $15 \%$ of the cohort reported short sleep duration $(<6 \mathrm{~h} /$ day) (table 2) and one-fourth and onethird of cohort members reported sleeping 7 or $8 \mathrm{~h}$ daily. Overweight-at-risk was associated with short sleep among women (adjusted ORs $(\mathrm{AOR})=1.33$, 95\% CI 1.18 to 1.51$)$. Obesity had a stronger association with short sleep for women $(\mathrm{AOR}=1.49,95 \%$ CI 1.32 to 1.68) but was also associated with short sleep for men $(\mathrm{AOR}=1.36,95 \%$ CI 1.21 to 1.54$)$. Also noted was an association between long sleep duration and obesity for both sexes. 
Table 1 Distribution of socio-demographic attributes, health behaviours and chronic disease by weight outcomes and sex, Thai Cohort Study 2009

\begin{tabular}{|c|c|c|c|c|c|c|c|c|c|}
\hline \multirow[b]{3}{*}{ Covariates } & \multirow{3}{*}{$\begin{array}{l}\text { Overall, } \\
N=60569\end{array}$} & \multicolumn{8}{|c|}{ Weight outcomes by sex* } \\
\hline & & \multicolumn{2}{|c|}{ Underweight } & \multicolumn{2}{|c|}{ Normal } & \multicolumn{2}{|c|}{ Overweight } & \multicolumn{2}{|c|}{ Obese } \\
\hline & & M & $\mathbf{F}$ & M & $\mathbf{F}$ & $\mathbf{M}$ & $\mathbf{F}$ & M & $\mathbf{F}$ \\
\hline Age (mean in years) & 35.6 & 33.0 & 30.1 & 35.5 & 33.7 & 38.6 & 36.5 & 39.6 & 36.8 \\
\hline \multicolumn{10}{|l|}{ Marital status } \\
\hline Married & 55.3 & 38.2 & 33.7 & 54.5 & 49.1 & 67.9 & 60.2 & 70.9 & 55.2 \\
\hline Single & 37.9 & 57.1 & 61.5 & 40.2 & 42.5 & 26.3 & 30.5 & 24.4 & 36.2 \\
\hline Separated/widowed & 6.8 & 4.7 & 4.8 & 5.3 & 8.4 & 5.8 & 9.3 & 4.8 & 8.6 \\
\hline \multicolumn{10}{|c|}{ Personal income (baht/month) } \\
\hline Up to 3000 & 5.9 & 15.6 & 6.3 & 7.1 & 5.5 & 4.8 & 5.3 & 4.7 & 6.1 \\
\hline $3000-7000$ & 12.9 & 18.7 & 18.6 & 11.8 & 15.0 & 8.1 & 14.6 & 7.5 & 14.5 \\
\hline $7000-10000$ & 22.4 & 26.6 & 32.4 & 20.5 & 27.5 & 14.7 & 23.2 & 13.3 & 23.0 \\
\hline $10000-20000$ & 35.7 & 27.8 & 31.7 & 39.1 & 33.9 & 41.3 & 32.7 & 38.2 & 31.5 \\
\hline$>20000$ & 23.1 & 11.3 & 11.0 & 21.5 & 18.1 & 31.1 & 24.3 & 36.4 & 24.9 \\
\hline \multicolumn{10}{|l|}{ Geographical residence } \\
\hline Rural & 44.0 & 50.8 & 42.9 & 48.5 & 42.7 & 45.2 & 42.8 & 42.6 & 39.9 \\
\hline Urban & 56.0 & 49.2 & 57.0 & 51.6 & 57.3 & 54.8 & 57.2 & 57.4 & 60.1 \\
\hline \multicolumn{10}{|l|}{ Smoking } \\
\hline Never & 76.8 & 61.4 & 97.1 & 57.4 & 97.0 & 50.7 & 96.5 & 47.2 & 95.2 \\
\hline Former & 14.3 & 17.7 & 2.2 & 23.9 & 2.3 & 31.3 & 2.8 & 33.6 & 3.9 \\
\hline Current & 8.9 & 20.9 & 0.8 & 18.7 & 0.7 & 18.0 & 0.7 & 19.2 & 0.9 \\
\hline \multicolumn{10}{|l|}{ Drinking (days/week) } \\
\hline 0 & 72.9 & 62.9 & 91.3 & 52.7 & 90.6 & 48.1 & 90.9 & 49.6 & 91.7 \\
\hline $1-3$ & 22.5 & 29.8 & 8.3 & 38.6 & 8.8 & 41.7 & 8.5 & 40.1 & 7.5 \\
\hline $4+$ & 4.6 & 7.3 & 0.4 & 8.7 & 0.6 & 10.2 & 0.5 & 10.3 & 0.9 \\
\hline \multicolumn{10}{|c|}{ Fruit and vegetable intake (serves/day) } \\
\hline $0-4$ & 41.8 & 48.8 & 39.9 & 44.1 & 38.6 & 43.3 & 38.9 & 46.6 & 41.7 \\
\hline $5+$ & 58.2 & 51.1 & 60.2 & 55.9 & 61.4 & 56.7 & 61.1 & 53.4 & 58.3 \\
\hline \multicolumn{10}{|c|}{ Physical activity (sessions/week) } \\
\hline $0-2$ & 19.4 & 18.8 & 22.7 & 13.5 & 21.7 & 14.2 & 23.8 & 18.8 & 25.2 \\
\hline $3+$ & 80.6 & 81.2 & 77.3 & 86.5 & 78.4 & 85.9 & 76.2 & 81.2 & 74.8 \\
\hline \multicolumn{10}{|l|}{ Screen time (h/day) } \\
\hline $0-4$ & 82.5 & 81.1 & 80.7 & 82.8 & 83.3 & 83.8 & 82.6 & 81.4 & 80.1 \\
\hline $5+$ & 11.5 & 18.9 & 19.3 & 17.2 & 16.7 & 16.2 & 17.4 & 18.6 & 19.9 \\
\hline $\begin{array}{l}\text { Ever been diagnosed } \\
\text { for chronic conditions } \dagger\end{array}$ & 30.3 & 20.2 & 20.0 & 26.8 & 23.6 & 36.1 & 31.2 & 48.0 & 36.9 \\
\hline $\begin{array}{l}\text { Ever been diagnosed } \\
\text { for depression }\end{array}$ & 1.8 & 2.3 & 2.0 & 1.6 & 1.6 & 1.4 & 1.9 & 2.0 & 2.6 \\
\hline
\end{tabular}

For longitudinal analysis, we performed multinomial logistic regression of sleep duration on incident weight gain, adjusting for the same covariates as for the crosssectional analyses. The dependent variable was substantive weight gain between 2005 and 2009, defined by three weight increase categories $(5 \%$ to $<10 \%, 10 \%$ to $<20 \%$ and $20+\%)$. Each category of weight gain was separately compared with no weight increase (ie, $<5 \%$ ) for calculation of ORs. Progressively larger increments in weight gain show progressively stronger significant associations with short sleep $(<6 \mathrm{~h})$, after adjusting for covariates $(\mathrm{AOR}=1.10,95 \% \mathrm{CI} 1.02$ to $1.20 ; \mathrm{AOR}=1.30,95 \%$ CI 1.18 to 1.44 and $\mathrm{AOR}=1.69,95 \%$ CI 1.39 to 2.05 ).

\section{DISCUSSION}

Our large cohort study revealed a consistent and substantial association between short sleep and obesity among Thai adults. Significant covariate AORs for the short sleep-obesity effect were 1.36 for men and 1.49 for women in 2009; corresponding ORs were similar in 2005. Longitudinal 2004-2009 cohort data confirmed a short sleep-weight gain relationship with a notable dose-response.

Cohort evidence from the USA is supportive. The Nurses Health Study analysed sleep and weight in a cohort of women for 16 years and found that those with $\leq 5 \mathrm{~h}$ sleep had more weight gain (additional 
Table 2 Association between sleep duration and weight outcomes, Thai Cohort Study 2009

\begin{tabular}{|c|c|c|c|c|}
\hline \multirow[b]{2}{*}{ Sleep duration } & \multirow[b]{2}{*}{$\begin{array}{l}\text { Overall, } \\
\mathrm{N}=60569 \\
\mathrm{n}(\%)\end{array}$} & \multicolumn{3}{|l|}{ Weight outcomes* } \\
\hline & & $\begin{array}{l}\text { Underweight } \\
\text { versus normal } \\
\text { AOR† }(95 \% \mathrm{Cl})\end{array}$ & $\begin{array}{l}\text { Overweight } \\
\text { versus normal } \\
\text { AOR } \dagger(95 \% \mathrm{Cl})\end{array}$ & $\begin{array}{l}\text { Obese } \\
\text { versus normal } \\
\text { AOR† }(95 \% \mathrm{Cl})\end{array}$ \\
\hline \multicolumn{5}{|c|}{ Sleep duration (men) } \\
\hline$<6 \mathrm{~h}$ & $4070(14.9)$ & $1.16(0.90$ to 1.50$)$ & $1.13(1.00$ to 1.28$)$ & 1.36 (1.21 to 1.52$)$ \\
\hline $6 \mathrm{~h}$ & $4815(17.6)$ & $0.90(0.71$ to 1.16$)$ & $0.98(0.88$ to 1.09$)$ & $1.16(1.04$ to 1.29$)$ \\
\hline $7 \mathrm{~h}$ & $5719(20.9)$ & Ref & Ref & Ref \\
\hline $8 \mathrm{~h}$ & $8664(31.6)$ & 1.15 (0.94 to 1.42$)$ & $1.06(0.97$ to 1.17$)$ & 1.08 (0.99 to 1.19$)$ \\
\hline$\geq 9 \mathrm{~h}$ & $4139(15.1)$ & $1.08(0.84$ to 1.39$)$ & $1.03(0.91$ to 1.16$)$ & $1.16(1.03$ to 1.30$)$ \\
\hline \multicolumn{5}{|c|}{ Sleep duration (women) } \\
\hline$<6 \mathrm{~h}$ & $4728(14.3)$ & $0.97(0.85$ to 1.11$)$ & $1.33(1.18$ to 1.51$)$ & 1.49 (1.32 to 1.68$)$ \\
\hline $6 \mathrm{~h}$ & $5120(15.4)$ & 0.99 (0.87 to 1.12$)$ & 1.21 (1.07 to 1.37$)$ & $1.28(1.14$ to 1.44$)$ \\
\hline $7 \mathrm{~h}$ & $6965(21.0)$ & Ref & Ref & Ref \\
\hline $8 \mathrm{~h}$ & $11007(33.2)$ & $1.05(0.95$ to 1.16$)$ & $1.13(1.02$ to 1.25$)$ & $1.14(1.04$ to 1.26$)$ \\
\hline$\geq 9 \mathrm{~h}$ & $5342(16.1)$ & $1.21 \neq(1.07$ to 1.37$)$ & $1.22(1.07$ to 1.39$)$ & 1.36 (1.20 to 1.53$)$ \\
\hline \multicolumn{5}{|c|}{$\begin{array}{l}\text { “Body mass index (BMI) categories: normal }=18.5 \text { to }<23 \text {; underweight }=\leq 18.5 \text {; overweight-at-risk }=23 \text { to }<25 \text {; obese }=\geq 25 \text {. For each } \\
\text { 'abnormal' category, multinomial logistic regression compares the outcome odds to the outcome odds of a 'normal' BMI, with the results } \\
\text { expressed as an Odd Ratio (OR). } \\
\text { †Adjusted ORs-covariates included age, marital status, personal income, geographical rural-urban residence, physical activity, fruit and } \\
\text { vegetable intakes, screen time, smoking, alcohol drinking, doctor-diagnosed depression and chronic health conditions (see the Methods } \\
\text { section). } \\
\text { fBolded values indicate statistical significance at } p<0.05 \text {. }\end{array}$} \\
\hline
\end{tabular}

$1.14 \mathrm{~kg}$ ) than those with $7 \mathrm{~h}$ sleep. Effects were more extreme with less sleep: for a $15 \mathrm{~kg}$ weight gain, Hazard Ratios (HRs) were 1.28 and 1.10 for $\leq 5$ and $6 \mathrm{~h}$, respectively. ${ }^{19}$ Even more extreme sleep deprivation was studied in a cohort of the US National Health and Nutrition Examination Survey over 9 years; for participants aged 32-49 years, the obesity OR was 3.21, for those with $\leq 4 \mathrm{~h}$ sleep compared with $7 \mathrm{~h}$ sleep. ${ }^{20} \mathrm{~A}$ prospective study of young Swiss adults also revealed a short sleep-obesity relationship: the effect was maximum at baseline (OR 7.4 at age 27 years) and attenuated after 13 years (OR 1.1 at age 40 years). ${ }^{22}$

Some longitudinal Asian evidence is also supportive. A national panel study in Korea reported an AOR of 1.25 (95\% CI 1.06 to 1.48 ) for $\leq 5 \mathrm{~h}$ sleep and obesity. ${ }^{25}$ For the same exposure-outcome categories, a cohort in Japan showed similar results with an AOR of $1.50(95 \%$ CI 1.10 to 2.10$).^{24}$

The search for mechanisms to link sleep and obesity is ongoing. One obvious pathway for those with short sleep is the increase in time available for eating. ${ }^{37}$ Also, fatigue associated with sleep deprivation leads to reduced exercise. ${ }^{38} 39$ And as already mentioned, appetite-regulating hormones such as leptin and ghrelin are expected to play a major biological role in linking short sleep and obesity. ${ }^{19} 40$ As well, other studies have drawn attention to obstructive sleep apnoea and when that condition occurs, there is a strong relationship to both short sleep and obesity. ${ }^{14} 17$

Our data also showed that some long-sleeping women were underweight, and other reports suggest that this may be related to comorbidity. ${ }^{41}{ }^{42}$ However, our results were adjusted for depression and 17 chronic health conditions, so we do not have an explanation to link long sleep and underweight. Nor do we understand the U-shaped risk pattern whereby both short and long sleep were associated with obesity in our Thai cohort. Such a pattern has been observed in other reports. ${ }^{8} 935$

We investigated personal environments and found that short sleep among our Thai cohort was more common for those who lack a fan or an air conditioner at home; at baseline in 2005, this affected $26 \%$ of short sleepers and $13 \%$ of others. However, we found no link between noisy home environments, hours of work, rural or urban location and short sleep duration. But we did note an occupational travel time effect: in 2005, short sleep was reported by $17 \%, 14 \%$ and $12 \%$ of those travelling $>1 \mathrm{~h}, 30 \mathrm{~min}$ to $1 \mathrm{~h}$ and $30 \mathrm{~min}$ to work, respectively.

One limitation of this study was the subjective nature of self-reporting sleep duration, a problem noted by many others conducting sleep research. ${ }^{9}{ }^{19}$ Weight and height of cohort members were also self-reported, but our previous validation study has found these numbers to be reliable. ${ }^{27}$ We also noted the relatively higher level of education among cohort members, but it is unclear how this could affect the results.

The strength of this study was the large sample, longitudinal data, national representation, involvement of young adults and the opportunity to control for many covariates in the analyses. We noted similar crosssectional results for both 2005 and 2009 although on both occasions, cohort members were unaware of any hypothesised relationship between sleep and weight. Even more compelling was the evidence from the 4-year longitudinal analyses yielding similar results. 


\section{CONCLUSIONS}

Our large adult cohort in Thailand shows a consistent relationship between short sleep duration and obesity. This is one of the few sleep-obesity studies in a middleincome country, one of the first in Southeast Asia and one of only a few longitudinal studies investigating this topic worldwide. The epidemiological evidence available now points to a consistent, substantial and presumably causal association for adults but mechanisms should be further explored.

\section{Author footnote}

*Thailand: Jaruwan Chokhanapitak, Chaiyun Churewong, Suttanit Hounthasarn, Suwanee Khamman, Daoruang Pandee, Suttinan Pangsap, Tippawan Prapamontol, Janya Puengson, Yodyiam Sangrattanakul, Sam-ang Seubsman, Boonchai Somboonsook, Nintita Sripaiboonkij, Pathumvadee Somsamai, Duangkae Vilainerun, Wanee Wimonwattanaphan. Australia: Chris Bain, Emily Banks, Cathy Banwell, Bruce Caldwell, Gordon Carmichael, Tarie Dellora, Jane Dixon, Sharon Friel, David Harley, Matthew Kelly, Tord Kjellstrom, Lynette Lim, Roderick McClure, Anthony McMichael, Tanya Mark, Adrian Sleigh, Lyndall Strazdins, Vasoontara Yiengprugsawan.

Acknowledgements We thank the staff at Sukhothai Thammathirat Open University (STOU) who assisted with student contact and the STOU students who are participating in this cohort study. We also thank Dr Bandit Thinkamrop and his team from Khon Kaen University for guiding us through the complex data process

Funding This study was supported by the International Collaborative Research Grants Scheme with joint grants from the Wellcome Trust UK (GR071587MA) and the Australian National Health and Medical Research Council (268055) and as a Global Health grant from the NHMRC (585426).

Competing interests None.

Patient consent Obtained

Ethics approval Ethics approval was obtained from Sukhothai Thammathirat Open University Research and Development Institute (protocol 0522/10) and The Australian National University Human Research Ethics Committee (protocol 2004344 and 2009570). Informed written consent was obtained from all participants.

Contributors VY and CB conceptualised and designed the sleep study. AS and SS devised and directed the cohort study. VY analysed and drafted the manuscript, with input by AS. All authors approved the final manuscript submission.

Provenance and peer review Not commissioned; externally peer reviewed.

Data sharing statement Additional unpublished data are available upon request, please contact Principal Investigators Professor Adrian C Sleigh (adrian.sleigh@anu.edu.au) or Associate Professor Sam-ang Seubsman (sam-ang.seu@stou.ac.th).

\section{REFERENCES}

1. Kronholm E, Partonen T, Laatikainen T, et al. Trends in self-reported sleep duration and insomnia-related symptoms in Finland from 1972 to 2005: a comparative review and re-analysis of Finnish population samples. J Sleep Res 2008;17:54-62.

2. Knutson KL, Van Cauter E, Rathouz PJ, et al. Trends in the prevalence of short sleepers in the USA: 1975-2006. Sleep 2010;33:37-45.

3. Rowshan Ravan A, Bengtsson C, Lissner L, et al. Thirty-six-year secular trends in sleep duration and sleep satisfaction, and associations with mental stress and socioeconomic factors-results of the Population Study of Women in Gothenburg, Sweden. J Sleep Res 2010;19:496-503.

4. Silva GE, Goodwin JL, Parthasarathy S, et al. Longitudinal association between short sleep, body weight, and emotional and learning problems in Hispanic and Caucasian children. Sleep 2011;34:1197-205.

5. Taveras EM, Rifas-Shiman SL, Oken E, et al. Short sleep duration in infancy and risk of childhood overweight. Arch Pediatr Adolesc Med 2008;162:305-11.
6. Horne J. Short sleep is a questionable risk factor for obesity and related disorders: statistical versus clinical significance. Biol Psychol 2008;77:266-76.

7. Nielsen LS, Danielsen KV, Sorensen TI. Short sleep duration as a possible cause of obesity: critical analysis of the epidemiological evidence. Obes Rev 2010;12:78-92.

8. Patel SR, Hu FB. Short sleep duration and weight gain: a systematic review. Obesity (Silver Spring) 2008;16:643-53.

9. Marshall NS, Glozier N, Grunstein RR. Is sleep duration related to obesity? A critical review of the epidemiological evidence. Sleep Med Rev 2008;12:289-98.

10. Cizza G, Requena M, Galli G, et al. Chronic sleep deprivation and seasonality: implications for the obesity epidemic. J Endocrinol Invest 2011;34:793-800.

11. Hancox RJ, Landhuis CE. Association between sleep duration and haemoglobin A1c in young adults. J Epidemiol Community Health. Published Online First: 7 November 2011. doi:10.1136/jech-2011200217

12. Pervanidou $P$, Chrousos GP. Stress and obesity/metabolic syndrome in childhood and adolescence. Int J Pediatr Obes 2011;6(Suppl 1):21-8.

13. Bonsignore MR, McNicholas WT, Montserrat JM, et al. The adipose tissue in obesity and obstructive sleep apnoea. Eur Respir J. Published Online First: 15 September 2011. doi:10.1183/ 09031936.00047010

14. Sanchez-de-la-Torre M, Mediano O, Barcelo A, et al. The influence of obesity and obstructive sleep apnea on metabolic hormones. Sleep Breath. Published Online First: 13 September 2011. doi:10.1007/ s11325-011-0552-7

15. Knutson KL, Van Cauter E. Associations between sleep loss and increased risk of obesity and diabetes. Ann NY Acad Sci 2008;1129:287-304.

16. Peppard PE, Young T, Palta M, et al. Longitudinal study of moderate weight change and sleep-disordered breathing. JAMA 2000;284:3015-21.

17. Young T, Skatrud J, Peppard PE. Risk factors for obstructive sleep apnea in adults. JAMA 2004;291:2013-16.

18. Buxton OM, Marcelli E. Short and long sleep are positively associated with obesity, diabetes, hypertension, and cardiovascular disease among adults in the United States. Soc Sci Med 2010;71:1027-36.

19. Patel SR, Malhotra A, White DP, et al. Association between reduced sleep and weight gain in women. Am J Epidemiol 2006; 164:947-54.

20. Gangwisch JE, Malaspina D, Boden-Albala B, et al. Inadequate sleep as a risk factor for obesity: analyses of the NHANES I. Sleep 2005;28:1289-96

21. Chaput JP, Despres JP, Bouchard C, et al. The association between sleep duration and weight gain in adults: a 6-year prospective study from the Quebec Family Study. Sleep 2008;31:517-23.

22. Hasler G, Buysse DJ, Klaghofer R, et al. The association between short sleep duration and obesity in young adults: a 13-year prospective study. Sleep 2004;27:661-6.

23. Lopez-Garcia E, Faubel R, Leon-Munoz L, et al. Sleep duration, general and abdominal obesity, and weight change among the older adult population of Spain. Am J Clin Nutr 2008;87:310-16.

24. Kobayashi D, Takahashi O, Deshpande GA, et al. Association between weight gain, obesity, and sleep duration: a large-scale 3-year cohort study. Sleep Breath. Published Online First: 3 September 2011. doi:10.1007/s11325-011-0583-0

25. Park SE, Kim HM, Kim DH, et al. The association between sleep duration and general and abdominal obesity in Koreans: data from the Korean National Health and Nutrition Examination Survey, 2001 and 2005. Obesity (Silver Spring) 2009;17:767-71.

26. Sleigh AC, Seubsman SA, Bain C. Cohort profile: The Thai Cohort of 87,134 Open University students. Int J Epidemiol 2008;37:266-72.

27. Lim LL, Seubsman SA, Sleigh A. Validity of self-reported weight, height, and body mass index among university students in Thailand: implications for population studies of obesity in developing countries. Popul Health Metr 2009;7:15.

28. Yiengprugsawan V, Stephan K, McClure R, et al. Risk factors for injury in a national cohort of 87,134 Thai adults. Public Health 2012;126:33-9.

29. Yiengprugsawan V, Seubsman S, Lim L, et al. Use and foregone health services among a cohort of 87,134 adult open university students in Thailand. Southeast Asian J Trop Med Public Health 2009;40:1347-58.

30. Seubsman SA, Kelly M, Sleigh A, et al. Methods used for successful follow-up in a large scale national cohort study in Thailand. BMC Res Notes 2011;4:166

31. Kanazawa M, Yoshiike N, Osaka T, et al. Criteria and classification of obesity in Japan and Asia-Oceania. Asia Pac J Clin Nutr 2002;11 (Suppl 8):S732-7. 
32. Banwell C, Lim L, Seubsman SA, et al. Body mass index and healthrelated behaviours in a national cohort of 87,134 Thai open university students. J Epidemiol Community Health 2009;63:366-72.

33. Seubsman SA, Lim LL, Banwell C, et al. Socioeconomic status, sex, and obesity in a large national cohort of 15-87-year-old open university students in Thailand. J Epidemiol 2010;20:13-20.

34. Banks E, Lim L, Seubsman SA, et al. Relationship of obesity to physical activity, domestic activities, and sedentary behaviours: cross-sectional findings from a national cohort of over 70,000 Thai adults. BMC Public Health 2011;11:762.

35. Magee CA, Iverson DC, Caputi P. Sleep duration and obesity in middle-aged Australian adults. Obesity (Silver Spring) 2009;18:420-1.

36. Mozaffarian D, Hao T, Rimm EB, et al. Changes in diet and lifestyle and long-term weight gain in women and men. $N$ Engl J Med 2011;364:2392-404.

37. St-Onge MP, Roberts AL, Chen J, et al. Short sleep duration increases energy intakes but does not change energy expenditure in normal-weight individuals. Am J Clin Nutr 2011;94:410-16.
38. Benedict C, Hallschmid M, Lassen A, et al. Acute sleep deprivation reduces energy expenditure in healthy men. Am J Clin Nutr 2011;93:1229-36.

39. Resnick HE, Carter EA, Aloia M, et al. Cross-sectional relationship of reported fatigue to obesity, diet, and physical activity: results from the third national health and nutrition examination survey. J Clin Sleep Med 2006;2:163-9.

40. Taheri S, Lin L, Austin D, et al. Short sleep duration is associated with reduced leptin, elevated ghrelin, and increased body mass index. PLoS Med 2004;1:e62.

41. Stranges S, Dorn JM, Shipley MJ, et al. Correlates of short and long sleep duration: a cross-cultural comparison between the United Kingdom and the United States: the Whitehall II Study and the Western New York Health Study. Am J Epidemiol 2008;168: 1353-64.

42. Lyytikainen $\mathrm{P}$, Rahkonen $\mathrm{O}$, Lahelma $\mathrm{E}$, et al. Association of sleep duration with weight and weight gain: a prospective follow-up study. $J$ Sleep Res 2011;20:298-302. 